\title{
Effect of Incorporation of Black Pepper and Cardamom on Quality Characteristics of Paneer
}

\author{
Richa Badola $^{1 *}$, Mohd Danish ${ }^{1}$, Sanjay Kumar ${ }^{2}$, Mohd Fahad ${ }^{1}$, Pavan Prakash Kanade ${ }^{3}$, \\ Shuchi Upadhayay ${ }^{1}$, Deepika Kohli ${ }^{1}$ and Indra Rautela ${ }^{4}$
}

\author{
${ }^{1}$ Department of Food Technology, UCALS, Uttaranchal University, Dehradun, Uttarakhand-248007, India \\ ${ }^{2}$ Food Technology Division, Graphic Era, Karnal, Dehradun, Uttarakhand-248007, India \\ ${ }^{3}$ Dairy Technology Division, ICAR-National Dairy Research Institute, Karnal, Haryana-132001, India \\ ${ }^{4}$ Department of Biotechnology, UCALS, Uttaranchal University, Dehradun, Uttarakhand-248007, India
}

*Corresponding author:richa.ucals@gmail.com

\begin{abstract}
Paneer is an indigenous dairy product which is relished by all and has high nutritional value, but has poor shelf-life. While herbs are known to be effective natural preservative, antioxidant and flavouring agent. Thus the present study was designed to develop herbal paneer by incorporating herbs viz., black pepper $(0.25 \%)$ and cardamom powder $(0.50 \%)$ and its quality parameters $(\mathrm{pH}$, titratable acidity, TSS, moisture content, ash content, fat content, protein content, phenolic content and sensory parameters) were evaluated and compared with control sample. The results revealed that the herbal paneer was organoleptically better than control samples, while no or least effects were found on the proximate and physiochemical parameters of the paneer. The total phenolic content was found to be slightly higher in herbal paneer sample, indicating possibility of use of herbs to develop a novel functional dairy product with enhanced antioxidant properties and ultimately enhanced shelf-life.
\end{abstract}

Keywords: Herbs, Paneer, Black pepper, Cardamom, Antioxidants, Total phenolic content

In the recent time, there has been an increasing trend of the consumers for foods fortified with natural ingredients or additives, due to increased consumers' health awareness and reports regarding possible toxicological effect of chemical preservatives. Also, natural antioxidants have emerged in the food market as a potential ingredient to prevent the auto oxidation of fats, oils and fat containing food products. Thus, herbs offer a promising natural alternative in food safety and fortification.

Herbs are aromatic plants that have a fleshy-juicy stem at young stage, while hard-woody tissue when 
they grow old. Their parts, for instance leaves, stems or seeds can be used as such, or can be dried and used later ${ }^{[1]}$. The herbs have been well known for their flavouring, medicinal, antioxidant and preservative properties $^{[2]}$. Studies indicate role of herbs in prolonging the shelf life of foods due to their bacteriostatic or bactericidal activity and also prevention in food rancidity due to their antioxidant activity ${ }^{[3]}$. Therefore, fortification of herbs in dairy products could provide a value added, functional dairy product with prolonged shelf-life.

Black pepper,Piper nigrum is very famous and commonly used throughout the world as medicinal and preservative agent. It has antioxidant and cleansing properties, and helps enhancing bioavailability of other herbs. It stimulates appetite,enhances digestion and circulation and helps to maintain respiratory system and joints health ${ }^{[4]} \cdot$ Cardamom, Eleltaria cardamomum is also very famous and occupies a high place in world trade, being high priced. It is used predominantly to flavor sweets, baked goods, tea and coffee. It is also used as food preservative owing to its antibacterial and antioxidant properties ${ }^{[5]}$.

Paneer (fresh cheese) is a traditional Indian acid-coagulated dairy product and carry a lot of market potential. It can be used in raw form or used in the preparation of several varieties of culinary dishes and fried snacks ${ }^{[6]}$. In India, it is estimated that $5 \%$ of the country's total milk production is converted into paneer and also that the annual production is approximately 150,000 tonnes ${ }^{[7]}$. However paneer has low shelf-life of only a day or two at ambient temperatures and 6-8 days at refrigeration temperature,owing to its high moisture content and being a rich source of nutrients. Besides these, poor handling and unhygienic processing conditions prevailing in unorganised sectors also results in its low shelf-life ${ }^{[8]}$. This, short shelf-life, is a major hurdle for conversion of cottage industry of paneer making into a large scale industrial process. Also, paneer provides a mode of preserving surplus milk (solids) and transporting it to the regions where either milk production is scarce or transportation is hard. The preserved form of paneer could prove to be very useful to defense forces or explorers in remote mountainous regions.

Food additives such as sorbic acid, potassium sorbate, $\mathrm{H}_{2} \mathrm{O}_{2}$, brine solution, Delvocid, Nisin, etc have been tried to increase shelf-life of paneer though they are not permitted additives to paneer. Thus, considering these above facts in view, the present study was designed to develop herbal paneer using black pepper and cardamom and the effect of herbs addition on the quality of paneer was examined.

\section{MATERIAL AND METHODS}

The present study was conducted at Food Technology Department of Uttaranchal University, Dehradun. All the raw materials (buffalo milk, black pepper, cardamom) were purchased from the local market of Premnagar, Dehradun, Uttarakhand. Herbs were finely ground into powder form and stored in airtight containers for later use. All the chemicals used for the preparation of different reagents were of Analytical Grade (AR) and were procured from standard companies. The reagents required for analysis were freshly prepared according to standard procedures.

\section{Preparation of herbal paneer}

Herbal paneer was prepared from buffalo milk with slight modification using standard method ${ }^{[9]}$ as narrated in Fig. 1, where $0.25 \%$ black pepper and $0.50 \%$ cardamom powder were added. Control sample was also prepared containing no added herbs. 


\section{Sensory analysis}

Sensory evaluation of samples was done by a panel of judges following 9-point hedonic scale ratings on the basis of colour, taste, flavour, texture and overall acceptability. The acceptability of the product was rated based on a scale of points ranging from "like extremely" to "dislike extremely".

\section{Proximate analysis}

Moisture content was calculated by standard method $^{[10]}$. The ash content of the sample was determined by the method of AACC ${ }^{[11]}$. Fat content was evaluated by Gerber centrifuge method ${ }^{[12]}$. Percent nitrogen content of the sample was estimated using the micro kjeldahl method ${ }^{[13]}$.

\section{Physico-chemical analysis}

Total Soluble solids (TSS) content was determined with Erma hand refractometer (Erma, Japan $0-32^{\circ} \mathrm{B}$ ) and expressed as ${ }^{\circ} \mathrm{Brix}$. $\mathrm{pH}$ was evaluated by digital handy $\mathrm{pH}$ meter. Total acidity was found by titration against $0.1 \mathrm{~N} \mathrm{NaOH}$ solution $^{[14]}$. Total phenolic content was estimated by colorimetric assay using the Folin-Ciocalteu reagent ${ }^{[15]}$.

\section{Statistical analysis}

Data was recorded as mean $\pm \mathrm{SD}$ of three independent replicates. The data were analyzed using MS-Excel 2010.

\section{RESULTS AND DISCUSSION}

The current examination has been done to analyze the effect of incorporation of black pepper and cardamom on proximate, physico-chemical and sensory properties of prepared paneer.

\section{Sensory parameters}

The result of sensory evaluation are represented in Figure 2 and it is clearly seen that the both paneer samples had a good response by the panellist and rated like moderately" in all the attributes of hedonic scale.

Fig. 1: Flowchart for preparation of herbal paneer 
The acceptability of any food product is influenced predominantly by its flavour. The changes in flavour score of paneer revealed that, there was a significant difference between flavour score of the paneer, when herbs were added. The changes in flavour score are presented in Fig. 2 and it can be seen that the herbal paneer sample was liked by the panellist. Body and texture of the product is an important sensory attribute; next to the flavour while examining organoleptic quality of most of the dairy products. The values pertaining to body and texture scores of paneer as affected by addition of herbs in paneer preparation can be seen in Fig. 2. The result regarding colour and appearance, the scores of paneer was affected by addition of herbs (Fig. 2). The colour and appearance is an important attribute. It determines the acceptability of a product on visual perception. The difference in the scores can be due to black-brown colour imparted to the paneer by herbs. The overall acceptability scores (Figure 2) were found to be slightly lower in herbal paneer, which might be due to the presence of large quantity of small brown and black coloured particles of herbs distributed throughout the body of the product, which is very uncommon for the paneer.

Similarly, it was reported that incorporation of coriander and mint at level of $10 \%$ by weight in paneer improved the overall acceptability score and yield of product ${ }^{[3]}$. While in another study, it was reported that the addition of turmeric in paneer prepared from either cow milk, buffalo milk or mix milk at the rate greater than $0.6 \%$ resulted into sharp decline in sensory score and texture of paneer but the sample were found still acceptable and safe for usage ${ }^{[16]}$.

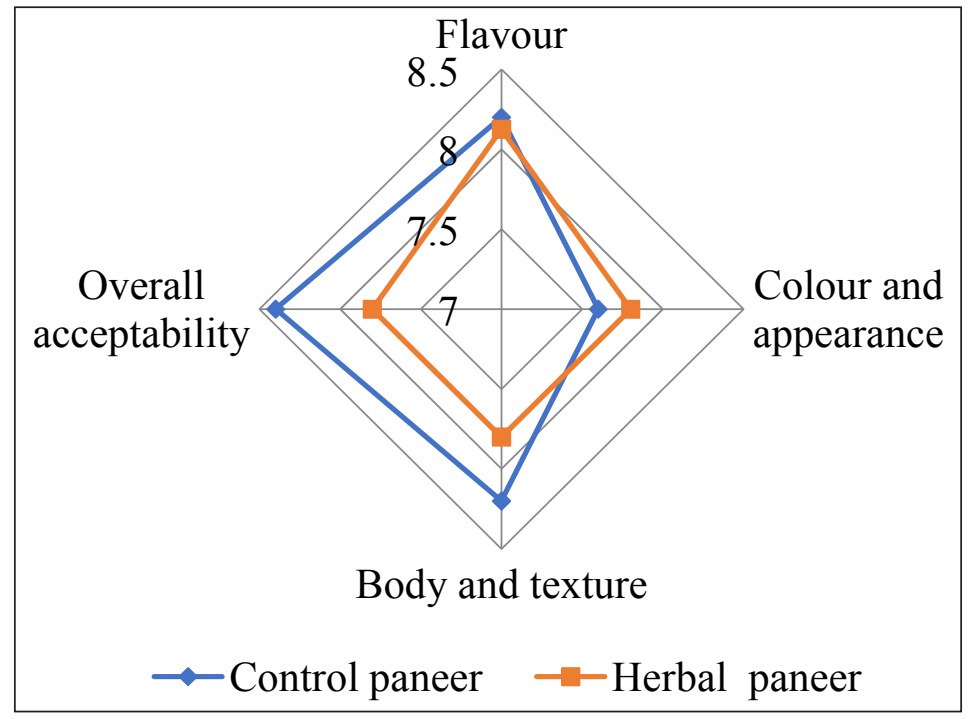

Fig. 2: Sensory properties of paneer samples

\section{Proximate analysis}

The results of proximate composition of prepared paneer samples are represented in Table 1. The moisture content of paneer samples were found to be in the range of 58.73-64.67\%. Similar moisture content values were reported by various researchers. In a study it was reported that the moisture content value of paneer to be $50.82 \%{ }^{[17]}$. In another study, seventy samples of fresh paneer from seven vendors of Ahmednagar city were evaluated for chemical quality and the average moisture content of market 
samples in the range of 42.62 to $60.39 \%$ was observed ${ }^{[18]}$. The fat content of paneer sample was found to be in the range of 25.2-25.7\% (Table 1). Similar fat content was observed in herbal paneer and control paneer samples. Previous studies reported fat value of paneer samples to be $25.2 \%{ }^{[17]}$ and in the range of 21.60 to $23.50 \%{ }^{[18]}$. Comparable protein content was observed in herbal paneer (12.66\%) and control paneer samples $(12.39 \%)$.In a study, it was observed that the average protein content in market samples of paneer in the range of 15.06 to $20.33 \%{ }^{[18]}$. The ash content of paneer sample was found to be in the range of $0.49-1.5 \%$ (Table 1). Higher ash content was observed in control paneer sample as compared to herbal paneer. Similar ash content values $(1.53 \%)$ were reported in a study ${ }^{[17]}$.

Table 1: Proximate composition of paneer samples

\begin{tabular}{ccc}
\hline Parameters & \multicolumn{2}{c}{ Paneer samples } \\
\cline { 2 - 3 } & Control & Herbal \\
\hline Moisture content, \% & $58.73 \pm 0.20$ & $64.67 \pm 0.20$ \\
Fat content, \% & $25.2 \pm 0.25$ & $25.7 \pm 0.3$ \\
Protein content, \% & $12.39 \pm 0.05$ & $12.66 \pm 0.14$ \\
Ash content, \% & $1.5 \pm 0.15$ & $0.49 \pm 0.02$ \\
\hline
\end{tabular}

Values are mean $\pm \mathrm{SD}(\mathrm{n}=3)$.

\section{Physico-chemical analysis}

The results of physico-chemical attributes of prepared beverages are represented in Table 2. $\mathrm{pH}$ was observed in paneer sample in the range of 4.8-5.8 and titratable acidity in the range $0.32-0.45 \%$. Higher total phenolic content was observed in herbal paneer sample $(0.472 \mathrm{mg}$ GAE/g) as compared to control paneer $(0.459 \mathrm{mg} \mathrm{GAE} / \mathrm{g})$ as observed in Table 2 . Antioxidants are the chemical substances that reduce or prevent oxidation and have the ability to counteract the damaging effects of free radicals in tissues, and thus are believed to protect against cancer, heart disease and several other diseases ${ }^{[19]}$.

Table 2: Physico-chemical parameters of paneer samples

\begin{tabular}{ccc}
\hline Parameters & \multicolumn{2}{c}{ Paneer samples } \\
\cline { 2 - 3 } & Control & Herbal \\
\hline $\mathrm{pH}$ & $5.63 \pm 0.15$ & $5.03 \pm 0.15$ \\
Titratable acidity, $\%$ & $0.32 \pm 0.02$ & $0.44 \pm 0.02$ \\
Total phenolic content, $\mathrm{mg} \mathrm{GAE} / \mathrm{g}$ & 0.459 & 0.472 \\
\hline
\end{tabular}

Values are mean $\pm \mathrm{SD}(\mathrm{n}=3)$.

\section{CONCLUSION}

The current study was designed for the utilization of herbs such as cardamom and black pepper to increase the utilization of paneer and thus avail-its health benefits in children and adults. Also, herbs provide nutritional as well as phyto-chemical benefits to human beings. In the present study, herbs (black pepper@0.25\% and cardamom powder@0.50\%) were incorporated and its effect on quality 
parameters was evaluated. The result of the study indicated that the addition of cardamom and black pepper had considerable effect on sensory attributes of paneer. Other parameters such as $\mathrm{pH}$, titratable acidity, TSS, moisture content, ash content, fat and protein content were found comparable to control sample. Differences in phenolic content represents that the herbal paneer had higher phenolic compounds as compared to control paneer and thus the prepared herbal paneer can be related with its associated health benefits. Hence, it can be said that the process for paneer production using herbs such as cardamom and black pepper is quite possible and provides an opportunity to use herb as a natural preservative to enhance its shelf-life, owing to herb's antioxidant and antimicrobial qualities.

\section{REFERENCES}

1. Firenzuoli, F. and Gori, L. 2007. Herbal medicine today: clinical and research issues. Evidence Based Complementary and Alternative Medicine, 4(S1): 37-40.

2. Soura, E.L., Stamford, T.L.M., Lima, E.O., Trajano, V.N. and Filho, M.B. 2005. Antimicrobial effectiveness of spices. International Journal of Biology, 41: 549-558.

3. Shelef, L.A. 1984. Antimicrobial effects of spices. Journal of Food Safety, 6: 29-44.

4. Damanhouri, Z.A. and Ahmad, A. 2014. A review on therapeutic potential of Piper nigrum L. Black Pepper: The King of Spices. Medicinal \& Aromatic Plants, 3: 1-6.

5. Govindarajan, V.S., Narasimhan, S., Raghuveer, K.G., Lewis, Y.S. and Stahl, W.H. 1982. Cardamom: production, technology, chemistry, and quality. Critical Reviews in Food Science \& Nutrition, 16(3): 229-326.

6. Aneja, R.P. 2007. East-West fusion of dairy products. In: Gupta S, editor. Dairy India Yearbook, A Dairy India Publication, New Delhi.

7. Singh, S. and Immanuel, G. 2014. Extraction of antioxidants from fruit peels and its utilization in paneer. Journal of Food Processing and Technology, 5(7): 349-351.

8. Gokhale, A.J., Mallek, J., Patel, S.M., Patel, A.M. and Pinto, S. 2016. Enhancement of shelf life of paneer by adopting hurdle technology. International Journal of Home Science, 2(2): 303-308.

9. Kumar, S., Rai, D.C. and Verma, D.N. 2008. Effect of fat levels on the physico-chemical and sensory attributes of buffalo milk paneer. Indian Veterinary Journal, 85(11): 1182-1184.

10. AOAC 2000. Official methods of analysis. Association of Official Analytical Chemists International. Maryland, USA.

11. AACC 2000. Approved methods of the American association of cereal chemists. Vol. 1. American Association for Cereal Chemist, St. Paul, MN.

12. IS: 1224 1997. Determination of fat by the Gerber method (part $2^{\text {nd }}$ ) milk product. Indian standard. Bureau of Indian Standards, Manak Bhavan, New Delhi.

13. AOAC 1990. Official methods of analysis. Association of Official Analytical Chemists International. Maryland, USA. 
14. Ranganna, S. 2002. Handbook of analysis of quality control for fruit and vegetable products, 2nd Edn, Tata McGraw Hill Publ. Co., New Delhi.

15. Singleton, V.L., Orthofer, R. and Lamuela-Raventos, R.M. 1999. Analysis of total phenols and other oxidation substrates and antioxidants by means of Folin-Ciocalteu reagent. Methods in Enzymology, 299: $152-178$.

16. Singh, R.R., Singh, R. and Shakya, B.R. 2014. Impact of turmeric addition on the properties of paneer, prepared from different types of milk. International Journal of Current Engineering and Technology, 4(3): 1874-1883.

17. Singh, S., Balasubramanyam, B.N. and Bhanu Murthi, J.L. 1991. Effect of addition of heat precipitated whey solids on the quality of paneer. Indian Journal of Dairy Science, 44: 178-180.

18. Desale, R.J., Dhole, P.T., Deshmukh, A.R. and Nimase, R.J. 2009. Studies on quality evaluation of market paneer. Asian Journal of Animal Science, 4(1): 73-74.

19. Ansari, M.M. and Kumar, D.S. 2012. Fortification of food and beverages with phytonutrients. Food Pub Health, 2(6): 241-253. 
